\title{
Science, Mathematics, And Engineering Graduate Students Bringing Computational Science Into The Pre-College Classroom.
}

\section{Eric Jakobsson}

University of Illinois at Urbana-Champaign, NCSA, 4021 Beckman Institute, 405 North Mathews Avenue, Urbana, IL 61801

The scientific enterprise in the United States, one of the major products of human civilization, is potentially on the verge of a crisis with respect to the supply of young scientists to continue the enterprise. Far fewer American youngsters are choosing scientific careers than in previous decades. Many factors have been postulated to contribute to this situation, and probably many of those hypotheses are true; it is unlikely that in a system with such complex dynamics as the interaction of science, education, and society that major trends would have only one cause. One line of thinking lays part of the blame on science teaching in the pre-college years. According to this argument, pre-college science teaching does not convey the reality, and especially the excitement, of the scientific discovery process.

The GK-12 program of the National Science Foundation (http://www.nsf.gov/home/crssprgm/gk12/start.htm) is designed to reform pre-college science education by engaging graduate students in science, mathematics, and engineering in partnerships with pre-college teachers to inject the substance and excitement of authentic, ongoing science into the classroom experience. It is expected that there will be both short- and long-term benefits. The short-term benefits arise directly from what the GK-12 Fellows accomplish in partnership with the classroom teachers. The long-term benefits are anticipated to arise from what both the Fellows and the partnering teachers take from their partnership. For the Fellows, it is an ongoing concern for education as a major component of their subsequent scientific and professional careers. For the partnering teachers, it is in motivation and expertise for the use of authentic science in the classroom.

The GK-12 program at the University of Illinois (http://www.ncsa.uiuc.edu/Divisions/eot/gk12/) is centered at the National Center for Supercomputing Applications (NCSA), located in the Beckman Insitute for Advanced Science and Technology, and also operates at two campuses of the University of Alabama, Birmingham and Huntsville. As one of the major Federallysupported campus-based supercomputing centers in the nation, NCSA has long been concerned about ease of usability as well as providing lots of compute cycles. A corollary to the development of usability tools has emerged, namely; when you make computational tools easier for scientists to use, you also make them accessible as tools for education. This has been the case in several educational projects that have come from NCSA/Beckman, notably Chickscope (http://chickscope.beckman.uiuc.edu/, utilizes MRI), Bugscope (http://bugscope.beckman.uiuc.edu/, utilizes electron microscopy), the Biology Student Workbench (http://peptide.ncsa.uiuc.edu/, utilizes Web-interfaced biology databases and analysis and visualization tools), and ChemViz (http://chemviz.ncsa.uiuc.edu/, utilizes computational chemistry modeling, simulation, and visualization tools). All of these projects make it possible for students to emulate the scientific process, in that they can use real scientific tools to validate hypotheses and even conduct original investigations. This mode of learning and teaching is so 
different from the usual that it requires a different context for planning and organization. This context is provided by a partner project, the Inquiry Page (http://inquiry.uiuc.edu/), which presents a template for planning inquiry-based learning and teaching activities. The Inquiry Page is centered in the Graduate School of Library and Information Science on the Illinois campus.

There is a strong synergy between the content and the influence of the above projects and the Illinois GK-12 program. Some recent and current activities in the Illinois GK-12 program include:

Two of our Fellows (Steve Moore (Cell and Structural Biology) and John Sabo (Microbiology)), working with two high school biology teachers (Paul Lock from Urbana and Kathy Gabric from Hinsdale) produced materials to guide their students in inferring evolutionary relationships from gene sequence analysis. (see http://www.district86.k12.il.us/central/faculty/kgabric/evolutionProject.htm)

Fellow Michael Kandianis (Plant Biology) worked with Champaign high school chemistry teachers Barry Rowe and Terry Coker to introduce hands-on computational explorations in the classes, employing ChemViz for detailed structural modeling and visualization, STELLA for kinetic modeling, and Java applets for demonstrating the statistical mechanical bases of thermodynamics. (See http://gk12.ncsa.uiuc.edu/Kandianis_files/frame.htm)

Fellow Dustin Lindley (Mathematics) worked with Professor Jerry Uhl to develop a Mathematica-based math course designed to prepare weak students( mathophobes, math refugees) in particular, but all students, for $1^{\text {st }}$ year college calculus. The key organizing concept is function, with other details in algebra and geometry following from that. The classroom partnering teacher was Sean Dannenfeldt, at the Technical Center of DuPage (TCD). The population of TCD is comprised of students who did not "make it" in other high schools, and are now learning trades (although a few do go on to further education). By extensive use of visualization of functions, and active engagement with an inquiry environment on individual laptops, the course seems to be succeeding in reaching students who might otherwise not be reachable. (See http://gk12.ncsa.uiuc.edu/Math116v2_files/frame.htm)

Fellow Smitha Sriram (Computer Science) has a project in progress with mathematics teacher Greg Hill at Hinsdale on the use of Java applets in place of textbooks and exams in a precalculus course. The present state of the project can be seen at Smitha's Inquiry Page site (http://inquiry.uiuc.edu/bin/update unit.cgi? command=select\&xmlfile=u11733.xml) .

In all of these cases, the GK-12 Fellows are using their developing professional and scientific skills and knowledge in the service of enriching pre-college classrooms with authentic computational science and mathematics. While it is too early to tell what the long-term benefits will be, what is happening in the short term is clearly highly beneficial. Our hope is that our project, and others like it, are contributing to a future where practicing scientists and engineers are also seriously committed to education, where pre-college science teachers have a real connection to the practice of science that enhances their teaching, and where students in the critical early years of their intellectual development are turned on to science, rather than turned away from science. 